\title{
Generation of action potential-type changes in response to darkening and illumination as indication of the plasma membrane proton pump status in Marchantia polymorpha
}

\author{
Kamila Kupisz $^{1}$ (D) $\cdot$ Halina Dziubińska ${ }^{1}$ Kazimierz Trębacz ${ }^{1}$
}

Received: 18 June 2016/Revised: 13 November 2016/ Accepted: 12 February 2017/Published online: 22 February 2017

(C) The Author(s) 2017. This article is published with open access at Springerlink.com

\begin{abstract}
The aim of the present study was to characterise bioelectrical changes in the membrane potential of Marchantia polymorpha gametophyte cells after light/dark transitions and to determine the role of the proton pump and energy status of the M. polymorpha cells in generation of these changes. Darkening caused persistent depolarisation of the resting potential (RP) and generation of shortlasting potential changes that were not uniform among different thalli. In some plants (18\%), the changes evoked by darkening were typical action potentials $\left(\mathrm{APs}_{\mathrm{dark}}\right)$, whereas in $69 \%$ of the plants, the changes had a form of action potential-like responses $\left(\mathrm{APs}_{\mathrm{dark}}\right.$-like) consisting of a transient depolarisation followed by a plateau phase, whose magnitude and duration were inconstant. The illumination of the $M$. polymorpha always evoked action potentials $\left(\mathrm{APs}_{\text {light }}\right)$ if the thallus was illuminated with light intensity of at least $120 \mu \mathrm{mol}$ photons $\mathrm{m}^{-2} \mathrm{~s}^{-1}$ after 30-min darkening. To analyse the involvement of $\mathrm{H}^{+}$ATPase in formation of the illumination/darkening-induced electrical responses in M. polymorpha, the proton pump regulators were used. The proton pump inhibitor $(20 \mu \mathrm{M}$ FCCP) significantly diminished the RP and inhibited darkinduced $\mathrm{AP}_{\text {dark }}$ and/or $\mathrm{AP}_{\text {dark }}$-like responses and illumination-induced $\mathrm{APs}_{\text {light }}$. After application of DCMU $(20 \mu \mathrm{M})$, the RP was strongly depolarised and no response to light/dark was observed. Fusicoccin $(20 \mu \mathrm{M})$, i.e., an activator of the proton pump, strongly hyperpolarised the
\end{abstract}

Communicated by J. Gao.

Kamila Kupisz

kamila.kupisz@ poczta.umcs.lublin.pl

1 Department of Biophysics, Institute of Biology and Biochemistry, Maria Curie-Skłodowska University, Akademicka 19, 20-033 Lublin, Poland membrane potential and blocked dark-induced $\mathrm{AP}_{\text {dark }} /$ $\mathrm{AP}_{\text {dark }}$-like responses and illumination-induced $\mathrm{APs}_{\text {light }}$.

Keywords Action potential · Light - Liverwort · Proton pump $\cdot$ Membrane potential

\section{Introduction}

Liverworts belong to the most basal lineage of land plants-embryophytes-located between algae and higher plants. The group is characterised by a gametophyte body as a dominant phase in the life cycle, fast growth, and morphological simplicity. The best molecularly characterised liverwort is Marchantia polymorpha, whose nucleus genome is being increasingly sequenced. Molecular analysis of the liverwort organellar genomes has been established with the complete sequence of the chloroplast (Ohyama et al. 1986) and mitochondrial DNAs (Oda et al. 1992; Oldenburg and Bendich 1998). Y-chromosomespecific clones from $M$. polymorpha have also been identified (Okada et al. 2000; Yamato et al. 2007). Moreover, thanks to the easy regeneration of thalli and the ability of young thalli to propagate from gemmae cups (vegetative propagules), M. polymorpha is an excellent object for a simple high-throughput production of transformed plants (Ishizaki et al. 2008; Kubota et al. 2013; Takenaka et al. 2000; Tsuboyama-Tanaka and Kodama 2015). Thus, $M$. polymorpha is being developed as a model plant with a critical evolutionary position to study specific molecular and cellular processes in detail.

As a nonvascular plant with the haploid generation as the dominant phase of the life cycle, $M$. polymorpha may serve as a convenient model for electrophysiological measurements, too. However, to date, there has been no 
report about the characteristics of electrical signals in $M$. polymorpha gamethophyte cells. Simultaneously, there are reports about intracellular investigations conducted on another liverwort Conocephalum conicum (Dziubińska et al. 1983; Favre et al. 1999b; Król et al. 2007; Zawadzki and Trębacz 1985) and on the moss Physcomitrella patens, a species that is phylogenetically related to liverworts and regarded as a model system in plant functional genomics (Decker et al. 2006; Reski 1999) and electrophysiology (Ermolayeva et al. 1996, 1997; Koselski et al. 2008, 2013, 2015). Conocephalum conicum displays excitability to various stimuli, such as light (Król and Trębacz 1999; Trębacz and Zawadzki 1985; Trębacz et al. 1989a), cold (Król et al. 2003; Kupisz and Trebacz 2011), wounding (Favre et al. 1999a), and direct current (DC) (Dziubińska et al. 1983; Król and Trębacz 1999; Paszewski et al. 1982). Among the stimuli mentioned above, light signals are considered as environmental factors that play a critical role in growth, reproduction, development, and regeneration, distinguishing liverworts, mosses, and other bryophytes from other plant species (Cove and Ashton 1988). At the plasma membrane level, illumination of the C. conicum liverwort with low light intensities causes a slow hyperpolarisation of the resting potential (RP), which is gradually overlaid by a faster depolarisation, whose amplitude increases depending on the intensity of the light stimulus (Trębacz et al. 1989a). After crossing the threshold value of light intensity, action potentials (APs) with relatively constant amplitudes occur (Trębacz and Zawadzki 1985). Light-dark transition evokes an opposite response in the range of subthreshold values: the thallus cells respond to darkening by generation of a transient hyperpolarisation of the membrane potential depending on light intensity (Trębacz et al. 1997, 1989a).

Gametophyte cells of $P$. patens generate APs both in response to illumination and darkening (Koselski et al. 2008). The amplitudes of APs evoked by illumination and darkening are similar and relatively constant, but the halftimes are different, i.e., light-induced APs are characterised by several times shorter half-time than APs evoked by darkening (Ermolayeva et al. 1996; Koselski et al. 2008). In the range of subthreshold values, electrical responses of the moss cells to light-dark transitions are opposite and symmetrical to the responses evoked by light stimulation, i.e., illumination evokes transient depolarisation first and then long-lasting hyperpolarisation, while darkening causes fast hyperpolarisation followed by long-lasting depolarisation (Ermolayeva et al. 1996; Koselski et al. 2008).

The aim of our study was to examine light- and darkinduced membrane potential changes in gametophytes of M. polymorpha. The fact that blue light-absorbing photoreceptor-phototropin (Komatsu et al. 2014) and a single copy of the phytochrome nuclear gene that encodes a photoreceptor protein mediating in developmental responses to red and far red light (Nishihama et al. 2015) have already been established in this liverwort additionally encouraged us to analyse the electrical changes in response to light. Moreover, Okumura et al. (2012) have defined eight isomers of $\mathrm{H}^{+}$-ATPase in $M$. polymorpha: four are penultimate threonine-containing $\mathrm{H}^{+}$-ATPases characteristic for vascular plants and four non-penultimate threonine-containing $\mathrm{H}^{+}$-ATPases such as in green algae. They have established that light causes activation of penultimate threonine-containing $\mathrm{H}^{+}$-ATPase and its photosynthesisdependence suggests that the model of the proton pump activation in the $M$. polymorpha liverwort is similar to the one observed in vascular plants (Okumura et al. 2012). Hence, our main task was to investigate the character of the membrane potential changes evoked by light/dark and to analyse the involvement of $\mathrm{H}^{+}$-ATPase in formation of the light-induced electrical responses in M. polymorpha.

\section{Results}

\section{General characteristics of darkening-induced membrane potential changes in Marchantia polymorpha cells}

Microelectrode recordings have shown that $100 \%$ of the tested M. polymorpha plants $(n=45)$ responded to sudden darkening first by generation of transient hyperpolarisation with relatively constant amplitude of $8.7 \pm 0.6 \mathrm{mV}$ and then by persistent depolarisation (Fig. 1). The magnitude of the persistent depolarisation did not depend on the intensity and time of illumination preceding darkening, but it was different among the plants and ranged between 5 and $82 \mathrm{mV}$. In $87 \%$ of the thalli, short-lasting potential changes were recorded against the background of the persistent depolarisation (Fig. 1). The membrane potential at the moment of generation of the short-lasting potential changes was named "initial membrane potential" $-V_{\text {initial }}$ (Fig. 1; Table 1) and a part of the persistent depolarisation between the resting potential (RP) recorded shortly before the dark stimulus onset and $V_{\text {initial }}$ was defined as "initial depolarisation". The final level of the membrane potential recorded in the plateau phase of the persistent depolarisation was marked out as $V_{\text {final }}$ (Fig. 1).

$18 \%$ of all the tested thalli $(n=8)$ generated the shortlasting potential changes in the form of an action potential $\left(\mathrm{AP}_{\text {dark }}\right)$ (Fig. 1b), whose average amplitude was $147.4 \pm 7.4 \mathrm{mV}$ and the half-time $\left(t_{1 / 2}\right)$ was $39.8 \pm 5.8 \mathrm{~s}$ (Table 1). In accordance with the all-or-none law, the amplitude of $\mathrm{APs}_{\text {dark }}$ did not depend on the stimulus strength, i.e., on the intensity and time of the white light preceding darkening (Fig. 2). Interestingly, in individual 


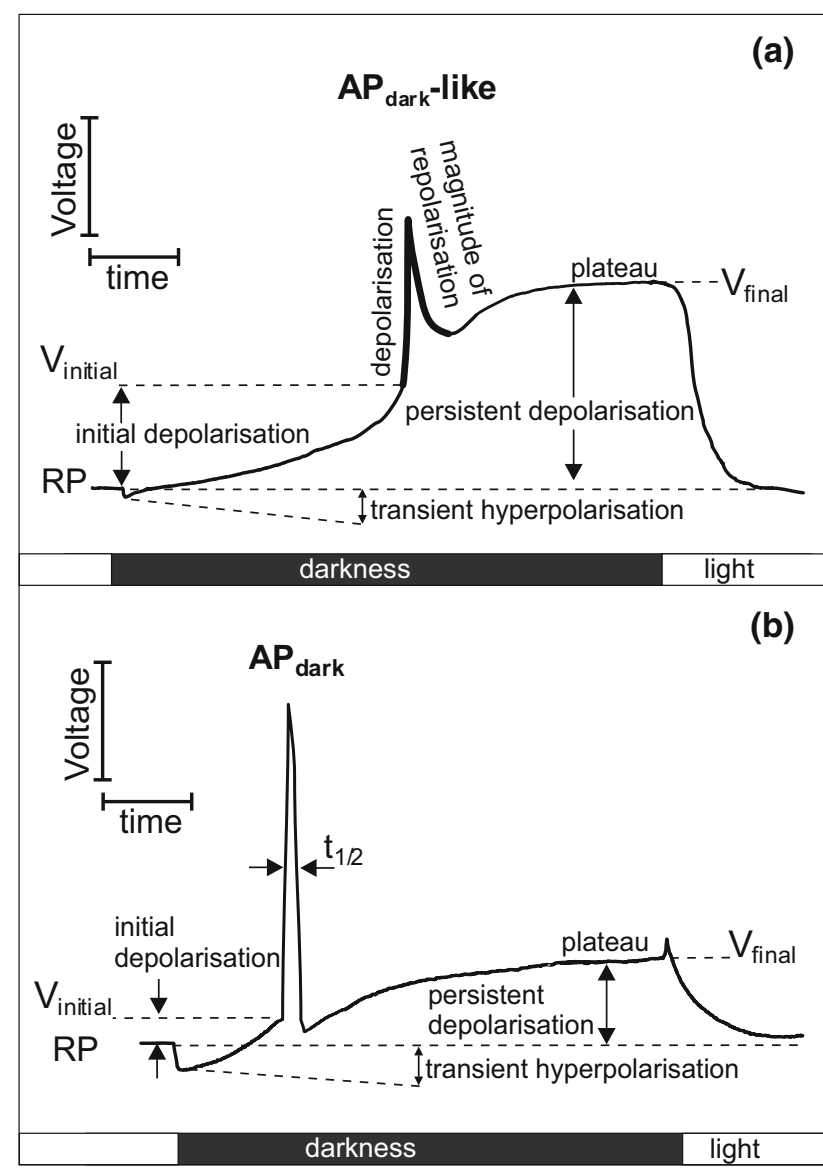

Fig. 1 Scheme of membrane potential changes evoked by darkening. Short-lasting potential change (bolded) - a change in a membrane potential in the form of $\mathbf{a}$ action potential-like response $\left(\mathrm{AP}_{\text {dark }}\right.$-like $)$ or b action potential $\left(\mathrm{AP}_{\text {dark }}\right) \cdot R P$ resting potential - a membrane potential of a thallus cell at rest (under white light of $40 \mu \mathrm{mol} \mathrm{m} \mathrm{m}^{-2} \mathrm{~s}^{-1}$ ), "transient hyperpolarisation" - a transient change in the membrane potential more negative than the resting potential, "persistent depolarisation"- a long-lasting change in the membrane potential less negative than the resting potential, "depolarisation" - a phase of the short-lasting potential change $\left(\mathrm{AP}_{\text {dark }}\right.$ and/or $\mathrm{AP}_{\text {dark }}$-like) registered on the background of the persistent depolarisation, defined as a rapid change in a membrane potential more positive than the resting potential, "magnitude of repolarisation"-a magnitude of a change in the membrane potential returning it to a level of the persistent depolarisation, $t_{1 / 2}$-half-time of $\mathrm{AP}_{\text {dark }}$ and/or $\mathrm{AP}_{\text {dark }}$-like, $V_{\text {initial }}$-initial membrane potential - the membrane potential recorded at the moment of generation of the short-lasting potential change, "initial depolarisation"- a part of the persistent depolarisation between the resting potential recorded shortly before the dark stimulus onset, and $V_{\text {initial }}$, $V_{\text {final }}$-final membrane potential—a membrane potential recorded in the plateau phase of the persistent depolarisation. Black bar indicates dark stimulation; white bar indicates illumination

thalli (2 of 45), two or three $\operatorname{APs}_{\text {dark }}(1$ of 45$)$ were generated in response to darkening after 2-h illumination with light of $10 \mu \mathrm{mol}$ photons $\mathrm{m}^{-2} \mathrm{~s}^{-1}$.

To evoke $\mathrm{AP}_{\text {dark }}$, the threshold duration of illumination with $10 \mu \mathrm{mol}$ photons $\mathrm{m}^{-2} \mathrm{~s}^{-1}$ needs to be longer than 15 min or longer than $5 \mathrm{~min}$ in the case of the white light of $300 \mu \mathrm{mol}$ photons $\mathrm{m}^{-2} \mathrm{~s}^{-1}$ (Fig. 2). The intensity and duration of illumination had no influence on the number of $\mathrm{APs}_{\text {dark }}$. In most of the thalli, a single $\mathrm{AP}_{\text {dark }}$ was generated following $5 \mathrm{~min}$-as well as to 2-h lasting illumination. Similarly, the intensity of light preceding darkening was not a decisive parameter.

In $69 \%$ of the tested thalli $(n=31)$, the short-lasting potential changes had a form of action potential-like responses $\left(\mathrm{AP}_{\mathrm{dark}}\right.$-like) (Fig. 1a) with relatively fast transient depolarisation and a long-lasting plateau phase, whose magnitude and delay in respect to the fast depolarisation were not uniform (Fig. 3). The duration of illumination with given intensity influenced the magnitude of the repolarisation phase (Figs. 1a, 3a): the average value of the correlation coefficient $(n=31)$ calculated for the dependence between the magnitude of repolarisation and light duration was 0.98 . Moreover, in $29 \%$ of plants generating $\mathrm{AP}_{\text {dark }}$-like responses $(n=9)$, the magnitude of the repolarisation phase was twice or more times lower than the amplitude of the $\mathrm{AP}_{\text {dark }}$-like response, regardless of the stimulus strength (Fig. 3b; Table 1). In such cases, determination of the half-time $\left(t_{1 / 2}\right)$ of the $\mathrm{AP}_{\text {dark }}$-like was impossible. Therefore, we divided the $\mathrm{AP}_{\text {dark }}$-like responses into two main groups for more precise analysis: one with a finite half-time $\left(\mathrm{AP}_{\mathrm{dark}}\right.$-like $\left.t_{1 / 2}\right)$ and the other one with the infinite half-time $\left(\mathrm{AP}_{\text {dark }}\right.$-like $\left.t_{1 / 2}^{\infty}\right)$ (Fig. 3). The excitability threshold for the intensity and time of illumination preceding darkening was also hard to establish: $\mathrm{AP}_{\text {dark }}$-like responses appeared even after illumination with white light of $1 \mu \mathrm{mol}$ photons $\mathrm{m}^{-2} \mathrm{~s}^{-1}$ or for $1 \mathrm{~min}$. The average amplitude of $\mathrm{AP}_{\text {dark }}$-like $t_{1 / 2}$ was $81 \pm 4.3$ and $72.5 \pm 4.6 \mathrm{mV}$ for $\mathrm{AP}_{\text {dark }}$-like $t_{1 / 2}^{\infty}$ (Table 1). The duration of illumination with given intensity did not have a strong effect on the amplitude of $\mathrm{AP}_{\mathrm{dark}}$-like responses in comparison to the light duration-repolarisation dependence: the mean correlation coefficient $(n=31)$ calculated for the light duration-amplitude dependence was 0.3 . The average amplitude of $\mathrm{AP}_{\text {dark }}$-like responses differed significantly from the average amplitude of $\mathrm{APs}_{\text {dark }}$ (Table 1). The difference between the amplitudes was not covered even by the higher magnitude of the initial depolarisation. The initial depolarisation was $53.5 \pm 3.6 \mathrm{mV}$ for $\mathrm{AP}_{\text {dark }}$-like $t_{1 /}$ 2 and $52.3 \pm 4.0 \mathrm{mV}$ for $\mathrm{AP}_{\text {dark }}$-like $t_{1 / 2}^{\infty}$, whereas for $\mathrm{AP}_{\text {dark, }}$ it was $14.9 \pm 2.8 \mathrm{mV}$. The average lag-time was $8.9 \pm 1.6 \mathrm{~min}$ for $\mathrm{AP}_{\text {dark }}, 18.1 \pm 0.9 \mathrm{~min}$ for $\mathrm{AP}_{\text {dark }}$-like $t_{1 / 2}$, and $16.6 \pm 2.7 \mathrm{~min}$ for $\mathrm{AP}_{\text {dark }}$ like $t_{1 / 2}^{\infty}$. The rate of the persistent depolarisation until $\mathrm{APs}_{\text {dark }}$ generation (or until the beginning of the plateau phase in the case of absence of $\mathrm{AP}_{\text {dark }}$ and/or $\mathrm{AP}_{\text {dark }}$-like) differed statistically from the rate of the persistent depolarisation before $\mathrm{AP}_{\mathrm{dark}}$-like responses, too (Table 1). The value of the RP in plants generating different types of the short-lasting potential 
Table 1 Average values of parameters characterizing the thalli cells generating $\mathrm{AP}_{\text {dark }}, \mathrm{AP}_{\text {dark }}-1$ like $t_{1 / 2}$, and $\mathrm{AP}_{\text {dark }}-1$ ike $t_{1 / 2}^{\infty}$ after dark stimulation following $30 \mathrm{~min}$ illumination with $300 \mu \mathrm{mol}$ photons $\mathrm{m}^{-2} \mathrm{~s}^{-1}$ and $\mathrm{AP}_{\text {light }}$ after light stimulation with $300 \mu \mathrm{mol} \mathrm{photons}^{-2} \mathrm{~s}^{-1}$

\begin{tabular}{|c|c|c|c|c|c|c|c|}
\hline $\begin{array}{l}\text { Bioelectrical } \\
\text { response }\end{array}$ & $\mathrm{RP}(\mathrm{mV})$ & $V_{\text {initial }}(\mathrm{mV})$ & $\begin{array}{l}\text { Rate of persistent } \\
\text { depolarisation } \\
(\mathrm{mV} / \mathrm{min})\end{array}$ & $\begin{array}{l}\text { Amplitude } \\
(\mathrm{mV})\end{array}$ & $T_{1 / 2}(\mathrm{~s})$ & $\begin{array}{l}\text { Magnitude of } \\
\text { repolarisation } \\
(\mathrm{mV})\end{array}$ & $V_{\text {final }}(\mathrm{mV})$ \\
\hline \multicolumn{8}{|l|}{ Darkness } \\
\hline $\begin{array}{l}\text { No } \mathrm{AP}_{\text {dark }} / \mathrm{AP}_{\text {dark }^{-}} \\
\text {like }(n=6)\end{array}$ & $-169.8 \pm 11.7$ & - & $0.65 \pm 0.07$ & - & - & - & $-147.1 \pm 15.6$ \\
\hline $\operatorname{AP}_{\text {dark }}(n=11)$ & $-175.1 \pm 3.3$ & $-160.2 \pm 4.7$ & $0.8 \pm 0.2$ & $147.4 \pm 7.4$ & $39.8 \pm 5.8$ & $146.4 \pm 8.6$ & $-128.9 \pm 9.5$ \\
\hline \multicolumn{8}{|l|}{$\mathrm{AP}_{\text {dark }}$-like } \\
\hline$t_{1 / 2}(n=19)$ & $-177.8 \pm 3.7$ & $-124.3 \pm 4.4$ & $2.5 \pm 0.2^{\mathrm{ab}}$ & $81.0 \pm 4.3^{\mathrm{ab}}$ & $72 \pm 27^{\mathrm{b}}$ & $45.6 \pm 6.0^{\mathrm{b}}$ & $-65.6 \pm 4.0^{\mathrm{ab}}$ \\
\hline$t_{1 / 2}^{\infty}(n=17)$ & $-163.8 \pm 5.7$ & $-111.5 \pm 4.0^{\mathrm{a}}$ & $3.5 \pm 1.0^{\mathrm{ab}}$ & $71.3 \pm 4.5^{\mathrm{b}}$ & - & $15.9 \pm 4.1^{\mathrm{bc}}$ & $-48.8 \pm 2.6^{\mathrm{abc}}$ \\
\hline \multicolumn{8}{|l|}{ Light } \\
\hline $\operatorname{AP}_{\text {light }}(n=33)$ & $-170.1 \pm 4.4$ & $-128.7 \pm 5.3$ & - & $103.4 \pm 4.3$ & $44.4 \pm 3.0$ & $103.4 \pm 4.3$ & $-172.5 \pm 4.6$ \\
\hline
\end{tabular}

RP resting potential of thalli cells recorded after 3-h incubation with light intensity of $40 \mu \mathrm{mol}$ photons $\mathrm{m}^{-2} \mathrm{~s}^{-1}, V_{\text {initial }}-$ membrane potential at the moment of $\mathrm{AP}_{\text {dark }}, \mathrm{AP}_{\text {dark }}$-like $t_{1 / 2}, \mathrm{AP}_{\text {dark }}$-like $t_{1 / 2}^{\infty}$, or $\mathrm{AP}_{\text {light }}$ generation, $t_{1 / 2}$ - half-time of the action potential/action potential-like response, $V_{\text {final }}-$ membrane potential in the steady state recorded after generation of $\mathrm{AP}_{\text {dark }}$ and/or $\mathrm{AP}_{\text {dark }}$-like, and $n$-number of short-lasting potential changes

${ }^{a}$ Statistically significant difference between thalli generating a given type of the short-lasting potential changes and those in which $\mathrm{AP}_{\mathrm{dark}}$ and/or $\mathrm{AP}_{\text {dark }}$-like were not observed

${ }^{\mathrm{b}}$ Statistically significant difference between thalli generating $\mathrm{AP}_{\text {dark }}$-like responses and those in which $\mathrm{AP}_{\text {dark }}$ was observed

${ }^{c}$ Statistically significant difference between thalli generating $\mathrm{AP}_{\mathrm{dark}}$-like $t_{1 / 2}^{\infty}$ and those in which $\mathrm{AP}_{\mathrm{dark}}$-like $t_{1 / 2}$ responses were observed, $t$ test, $p<0.05$. Data show means with the standard errors

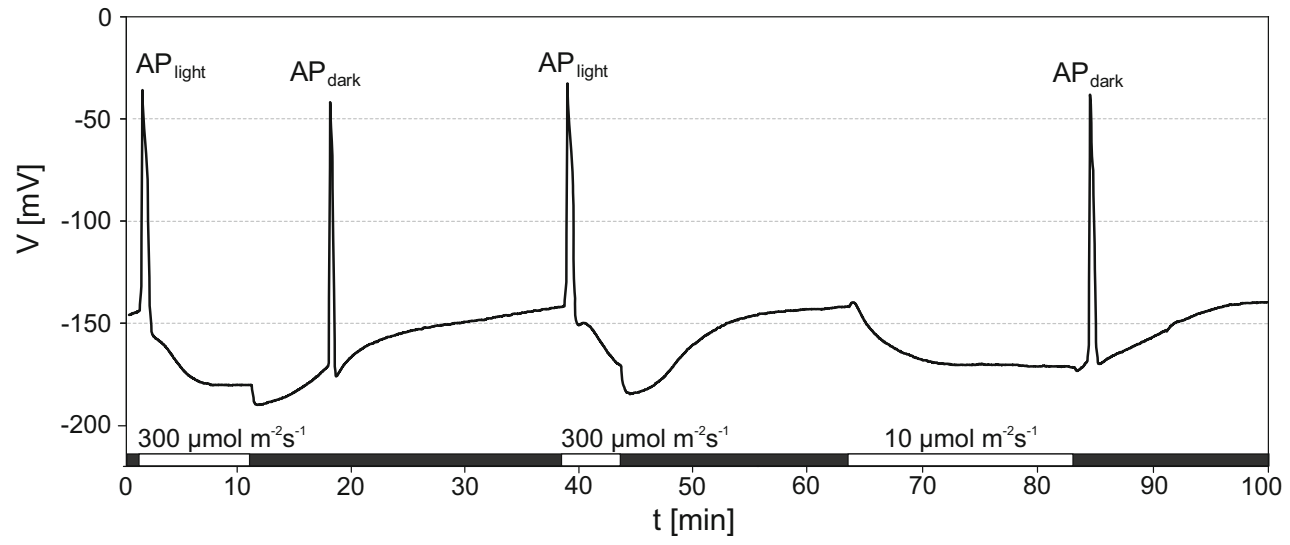

Fig. 2 All-or-none law for action potentials evoked by light/dark in Marchantia polymorpha cells immersed in the standard solution containing $1 \mathrm{mM} \mathrm{KCl}, 0.1 \mathrm{mM} \mathrm{CaCl} 2,50 \mathrm{mM}$ sorbitol, and Tris/ MES ( $\mathrm{pH} 7)$. Action potentials evoked by darkening $\left(\mathrm{AP}_{\mathrm{dark}}\right)$ and

changes did not differ statistically and was approx. $-170 \mathrm{mV}$. Simultaneously, the final level of the membrane potential recorded in the plateau phase of the persistent depolarisation $\left(V_{\text {final }}\right)$ was diverse: thalli generating $\mathrm{APs}_{\text {dark }}$-like $t_{1 / 2}^{\infty}$ responses were characterised by the most depolarised $V_{\text {final }}(-48.8 \pm 2.6 \mathrm{mV})$, while $V_{\text {final }}$ was the lowest $(-147.1 \pm 15.6 \mathrm{mV})$ in plants without $\mathrm{AP}_{\text {dark }}$ and/ illumination $\left(\mathrm{AP}_{\text {light }}\right)$ are labelled. Darkening (black bars) was applied after exposure of the thalli to white light $(300 \mu \mathrm{mol}$ photons $\mathrm{m}^{-2} \mathrm{~s}^{-1}$ or $10 \mu \mathrm{mol}$ photons $\mathrm{m}^{-2} \mathrm{~s}^{-1}$, as labelled) for the indicated time of illumination (white bars)

or $\mathrm{AP}_{\text {dark }}$-like (Table 1). Moreover, the higher the rate of the persistent depolarisation, the less negative the value of the $V_{\text {final }}$ and the lower the magnitude of the repolarisation phase. The absence of $\mathrm{AP}_{\text {dark }}$ and/or $\mathrm{AP}_{\text {dark }}$-like was noted for thalli $(n=6)$ in which darkening caused depolarisation of the membrane potential with the rate of $0.65 \pm 0.07 \mathrm{mV} / \mathrm{min}$ or less. 


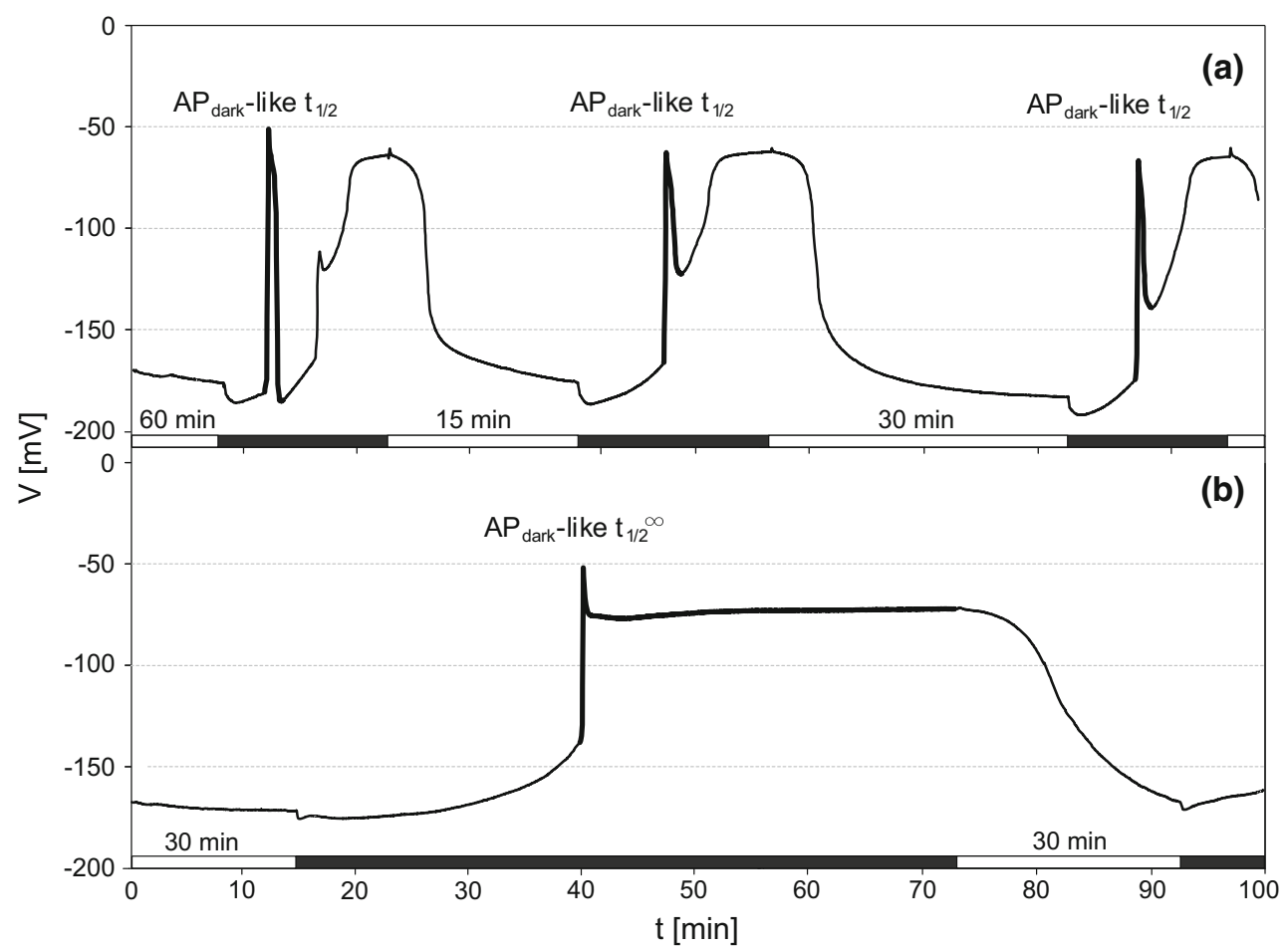

Fig. 3 Examples of traces of action potential-like responses: $\mathrm{AP}_{\mathrm{dark}^{-}}$ like $t_{1 / 2}$ (a) and $\mathrm{AP}_{\text {dark }}$-like $t_{1 / 2}^{\infty}$ (b) in two different thalli evoked by darkening. $\mathrm{AP}_{\text {dark }}$-like $t_{1 / 2}$-action potential-like response with finite half-time, and $\mathrm{AP}_{\text {dark }}$-like $t_{1 / 2}^{\infty}$-action potential-like response with

\section{General characteristics of illumination-induced membrane potential changes in Marchantia polymorpha cells}

Sudden illumination evoked transient depolarisation of the membrane potential that was proportional to the white light intensity and time of darkness preceding illumination. The stimulus strength dependence was registered for the intensities below approx. $120 \mu \mathrm{mol}$ photons $\mathrm{m}^{-2} \mathrm{~s}^{-1}$. Above these values, action potentials $\left(\mathrm{AP}_{\text {light }}\right)$ were generated with relatively constant amplitude of $103.4 \pm 4.3 \mathrm{mV}$ and half-time of $44.4 \pm 3.0 \mathrm{~s}$. Similarly, 17 min of darkness (without $\mathrm{AP}_{\text {dark }}$ ) and 18 min since $\mathrm{AP}_{\text {dark }}$ (or $\mathrm{AP}_{\text {dark }}$-like) generation were the minimal period of time necessary to evoke $\mathrm{AP}_{\text {light }}$ in response to $300 \mu \mathrm{mol}$ photons $\mathrm{m}^{-2} \mathrm{~s}^{-1}$ white light stimulation (Fig. 4). Marchantia polymorpha cells always generated one or no $\mathrm{AP}_{\text {light }}$, depending on the stimulus strength, in agreement with the all-or-none law. Moreover, $\mathrm{AP}_{\text {light }}$ evoked by the threshold white light intensity of $120 \mu \mathrm{mol}$ photons $\mathrm{m}^{-2} \mathrm{~s}^{-1}$ or the threshold time of darkness of $17 \mathrm{~min}$ were preceded by a generator potential (GP) (Fig. 4, inset). Apart from the strength of the stimulus, the magnitude of the membrane potential seems to play a crucial role in $\mathrm{AP}_{\text {light }}$ formation; $\mathrm{APs}_{\text {light }}$ have never been registered for a membrane potential higher than $-90 \mathrm{mV}$. infinite half-time. $\mathrm{AP}_{\mathrm{dark}}$-like responses $\left(t_{1 / 2}\right.$ and $t_{1 / 2}^{\infty}$, marked out, respectively) are bolded. Dark stimulus was applied after illumination of the thalli with light intensity of $300 \mu \mathrm{mol}$ photons $\mathrm{m}^{-2} \mathrm{~s}^{-1}$ for the indicated time (white bars)

Role of the proton pump in forming and generation of light-induced membrane potential changes in Marchantia polymorpha cells

The important role of the plasma membrane $\mathrm{H}^{+}$-ATPase in maintenance and post-excitation restoration of the RP is well established (Lopez-Marques et al. 2004; Orlova et al. 1997; Trębacz et al. 1994). Therefore, we used $\mathrm{H}^{+}$-ATPase modulators to investigate the role of the proton pump in electrogenesis of the $\mathrm{RP}$ and formation of $\mathrm{AP}_{\text {light }}, \mathrm{AP}_{\text {dark }}$, and $\mathrm{AP}_{\text {dark }}$-like responses. In our studies, application of FCCP (carbonyl cyanide-4-(trifluoromethoxy)phenylhydrazone) at a concentration of $20 \mu \mathrm{M}$ caused substantial depolarisation of the membrane potential in M. polymorpha thalli (Fig. 5a). The level of the RP in gametophyte cells after FCCP application depended on the inhibitor concentration; $20 \mu \mathrm{M}$ FCCP depolarised the RP to $-116.3 \pm 3.2 \mathrm{mV}(n=3)$, whereas $50 \mu \mathrm{M}$ FCCP caused depolarisation of the RP to $-60.3 \pm 5.9 \mathrm{mV} \quad(n=4)$ (Figs. 5a, inset, 6). Moreover, FCCP at $50 \mu \mathrm{M}$ and higher concentrations evoked short-lasting potential changes that resembled the ones generated by the thalli in response to darkening. In all cases $(n=7)$, the alternate light-dark and dark-light transitions caused only slow responses (depolarisation/hyperpolarisation for darkening/illumination, respectively), pointing to loss of plant excitability 
Fig. 4 All-or-none law for illumination-induced action potentials $\mathrm{AP}_{\text {light }}$ in Marchantia polymorpha cells immersed in the standard solution. White light of $300 \mu \mathrm{mol}$ photons $\mathrm{m}^{-2}$ $\mathrm{s}^{-1}$ was applied after the indicated time in darkness before illumination (black bars). The inset shows $\mathrm{AP}_{\text {light }}$ preceded by GP (generator potential) induced by $17-\mathrm{min}$ threshold time of darkness

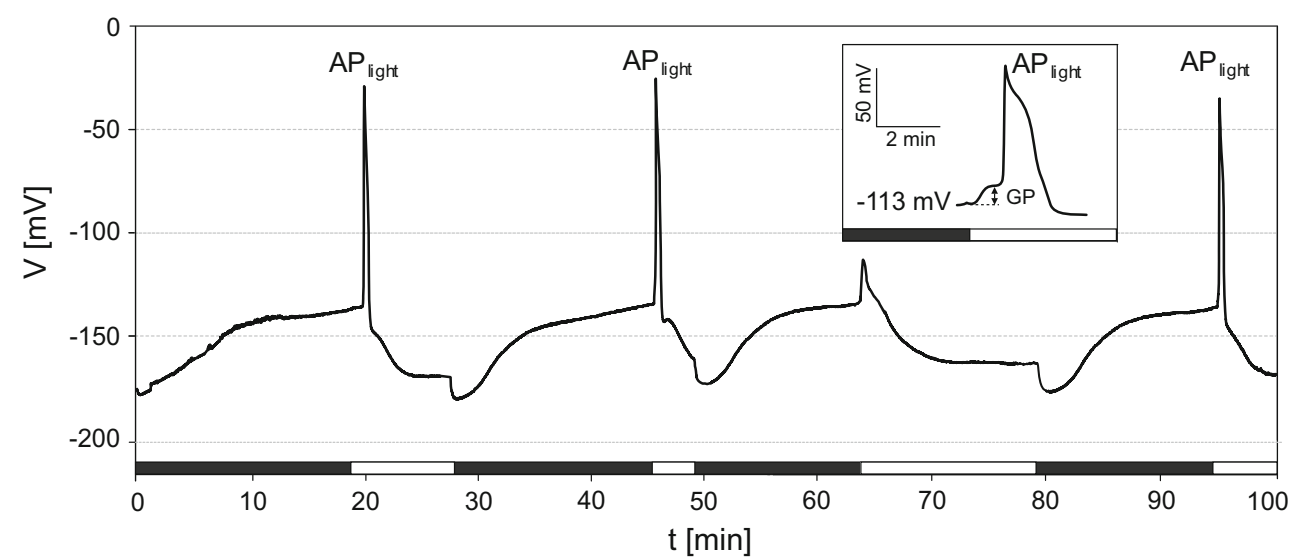

Fig. 5 Light- and dark-induced membrane potential changes in Marchantia polymorpha gametophyte cells immersed in the standard solution supplemented with a $20 \mu \mathrm{M}$ FCCP or b $20 \mu \mathrm{M}$ DCMU. The inset in a presents membrane potential changes in the cells treated with $50 \mu \mathrm{M}$ FCCP

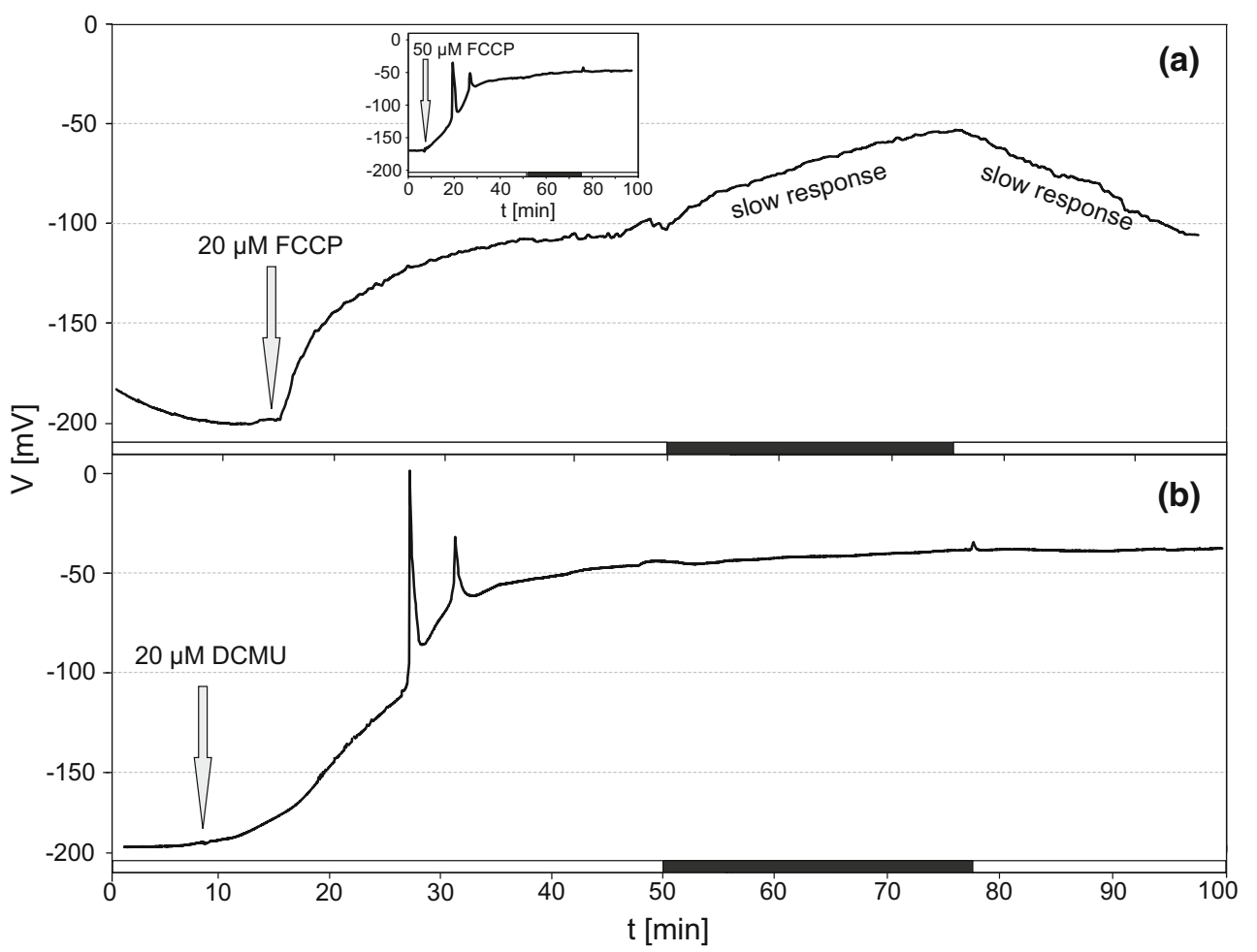

(Fig. 5a). The magnitude of the slow responses depended on the inhibitor concentration; it was $50.0 \pm 8.2 \mathrm{mV}$ for $20 \mu \mathrm{M} \mathrm{FCCP}$ and $19.6 \pm 3.7 \mathrm{mV}(n=4)$ for $50 \mu \mathrm{M}$ FCCP.

To analyse the involvement of photosynthesis in the light-induced electrical reaction, we blocked the photosynthetic electron transport chain with (3-(3,4-dichlorophenyl)-1,1-dimethylurea) DCMU. The addition of $20 \mu \mathrm{M}$ DCMU to the standard medium caused depolarisation of the RP to $-59.3 \pm 1.2 \mathrm{mV}(n=3)$ (Fig. 6) and generation of short-lasting potential changes (Fig. 5b). As in the case of FCCP, the plants lost their excitability after application of $20 \mu \mathrm{M}$ DCMU. Moreover, darkening evoked only slight slow responses with a magnitude of
$6.3 \pm 2.0 \mathrm{mV}(n=3)$, while illumination did not evoke any changes in the membrane potential. In all cases, dark stimulation in the inhibitor-treated plants caused depolarisation of the membrane potential to the level close to $V_{\text {final }}$ of plants generated $\mathrm{AP}_{\text {dark }}$-like responses in the standard medium (Fig. 6).

Fungal toxin fusicoccin (FC) was used as an $\mathrm{H}^{+}$-ATPase activator. In our study, 30-min plant incubation in the standard solution supplemented with $20 \mu \mathrm{M}$ fusicoccin was sufficient to hyperpolarise the RP to the average value of $-203.3 \pm 4.3 \mathrm{mV}(n=6)$ (Figs. 6, 7). Moreover, $\mathrm{AP}_{\text {light }}$, $\mathrm{AP}_{\text {dark }}$, and $\mathrm{AP}_{\text {dark }}$-like were not observed in M. polymorpha cells that generated a given type of response before fusicoccin supplementation. Interestingly, in the thalli that 


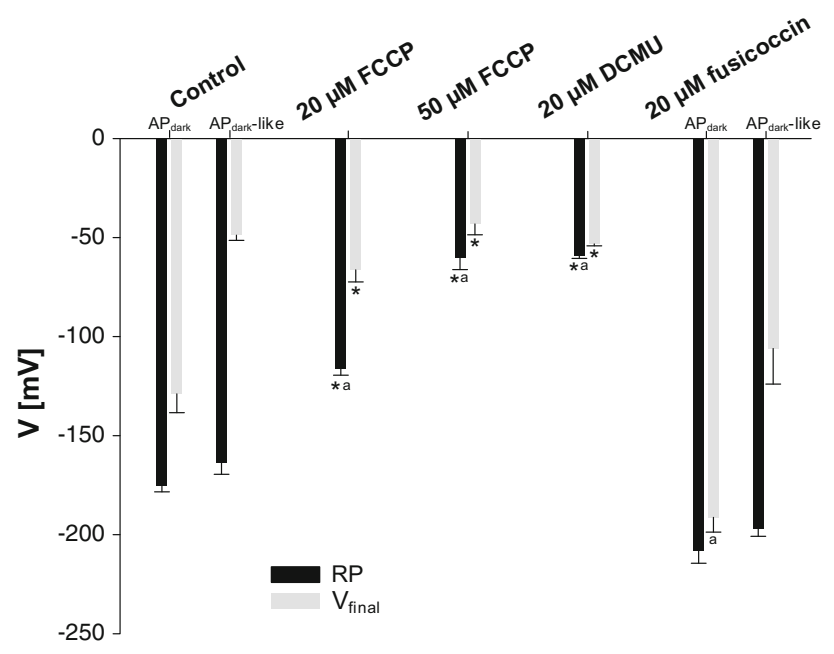

Fig. 6 Effects of proton pump modulators on the M. polymorpha resting potential recorded shortly before darkening (RP, black bars) and on the membrane potential established in the darkness after dark stimulation $\left(V_{\text {final }}\right.$, grey bars $)$. RP and $V_{\text {final }}$ have been detailed for the thalli generating two types of darkening-induced membrane potential changes $\left(\mathrm{AP}_{\text {dark }}\right.$ or $\mathrm{AP}_{\text {dark }}$-like) in the standard solution (control) and for the thalli immersed in the standard solution supplemented with $20 \mu \mathrm{M}$ fusicoccin, which generated $\mathrm{AP}_{\text {dark }}$ or $\mathrm{AP}_{\text {dark }}$-like responses (marked out, respectively) before the activator application. The number of each modulator-treated plants was not lower than 3. Data show means with the standard errors. *-Statistically significant difference between the respective treatments and the standard solution in which $\mathrm{AP}_{\text {dark }}$ was observed, $a$-statistically significant difference between the respective treatments and the standard solution in which

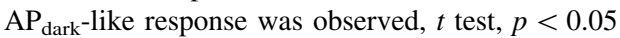

had generated $\mathrm{AP}_{\text {dark }}$-like responses, darkening evoked significant depolarisation of $88.3 \pm 16.9 \mathrm{mV} \quad(n=3)$, which was not observed in the thalli generating $\mathrm{AP}_{\text {dark }}$ or $\mathrm{AP}_{\text {light }}$ before the activator application (Fig. 7). However, $V_{\text {final }}$ in plants assigning to $\mathrm{AP}_{\text {dark }}$-like group did not differ statistically from the one obtained in the control solution (Fig. 6).

\section{Discussion}

It is well established that plants react to light by generation of membrane potential changes (Elzenga et al. 1995; Mimura and Tazawa 1986; Plieth et al. 1998; Szarek and Trebacz 1999). In the present study, we have demonstrated that darkening-induced membrane potential changes generated by the $M$. polymorpha liverwort are characterised by transient hyperpolarisation followed by persistent depolarisation and the short-lasting potential changes generated against the background of the depolarisation. The experiments have revealed the existence of two types of the shortlasting potential changes induced by darkening. The first type- $\mathrm{AP}_{\mathrm{dark}}$-was characterised by features typical for action potentials: it fulfilled the all-or-none law, according to which the maximum spike is reached once a stimulus is given and increasing the intensity of the stimulus does not increase the response amplitude. It possesses a refractory period, too. The second type of the short-lasting potential changes- $\mathrm{AP}_{\text {dark }}$-like-was the membrane potential change that resembled an action potential mainly in the kinetics of the transient depolarisation phase. The repolarisation phase of the $\mathrm{AP}_{\text {dark }}$-like responses possessed a lower magnitude than the depolarisation phase. Moreover, the existence of a strong dependence between the magnitude of the repolarisation phase and the stimulus strength within one thallus (correlation coefficient $=0.98$ ) suggests that transporters driving $\mathrm{K}^{+}$and/or $\mathrm{H}^{+}$ions that are postulated to be engaged in the repolarisation phase of APs (Trębacz et al. 1994) did not function properly during darkness in those thalli. In extreme cases, the plateau phase of the $\mathrm{AP}_{\text {dark }}$-like responses lasted until the moment of illumination that was necessary to induce the repolarisation of the membrane potential and the return to the level before the stimulation. Taking into account the repolarisation features mentioned above and the fact that the threshold value of the intensity and time of illumination preceding darkening (refractory period) was hard to establish, we regarded $\mathrm{AP}_{\text {dark }}$-like responses as not being typical action potentials. Interestingly, generation of $\mathrm{AP}_{\text {dark }}$ and/or $\mathrm{AP}_{\text {dark }}$-like after darkening and persistent depolarisation was observed in the moss P. patens (Koselski et al. 2008), but not in the liverwort $C$. conicum (Trębacz and Zawadzki 1985). The dark-induced $\mathrm{AP}_{\mathrm{dark}}$ in M. polymorpha was characterised by a several times shorter half-time (10-s range) than $\mathrm{AP}_{\text {dark }}$ registered in $P$. patens (10-min range) (Koselski et al. 2008). In M. polymorpha cells, illumination, in contrast to darkening, always evoked typical action potentials for the threshold and higher light intensities or generator potentials (GPs) for subthreshold light stimuli depending on the light intensity values. This rule is typical for C. conicum (Trębacz et al. 1989a) as well as for $P$. patens (Koselski et al. 2008). In M. polymorpha, no $\mathrm{AP}_{\text {light }}$ was recorded after application of the proton pump inhibitors. This observation is characteristic of C. conicum (Trębacz et al. 1989b) but not of P. patens (Koselski et al. 2008). Moreover, $\mathrm{AP}_{\text {light }}$-like responses after light stimulation were never recorded in all the tested $M$. polymorpha thalli, irrespective of the stimulus strength. This rule points to the different mechanisms engaged in the formation of $\mathrm{AP}_{\text {light }}$ and $\mathrm{AP}_{\text {dark }}$ or $\mathrm{AP}_{\text {dark }}$-like responses. However, in experiments performed on the moss $P$. patens, Koselski et al. (2008) did not observe differences between membrane potential changes evoked by illumination and darkening, except for having different kinetics.

The results from the experiments performed with the use of the proton pump inhibitors FCCP or DCMU imply that 
Fig. 7 Light- and dark-induced membrane potential changes in Marchantia polymorpha gametophyte cells treated with $20 \mu \mathrm{M}$ fusicoccin. The arrow points to the moment of the activator application. The panels show examples of traces of $\mathbf{a} \mathrm{AP}_{\text {light }}, \mathbf{b} \mathrm{AP}_{\text {dark }}$, and c $\mathrm{AP}_{\text {dark }}$-like responses recorded before fusicoccin application

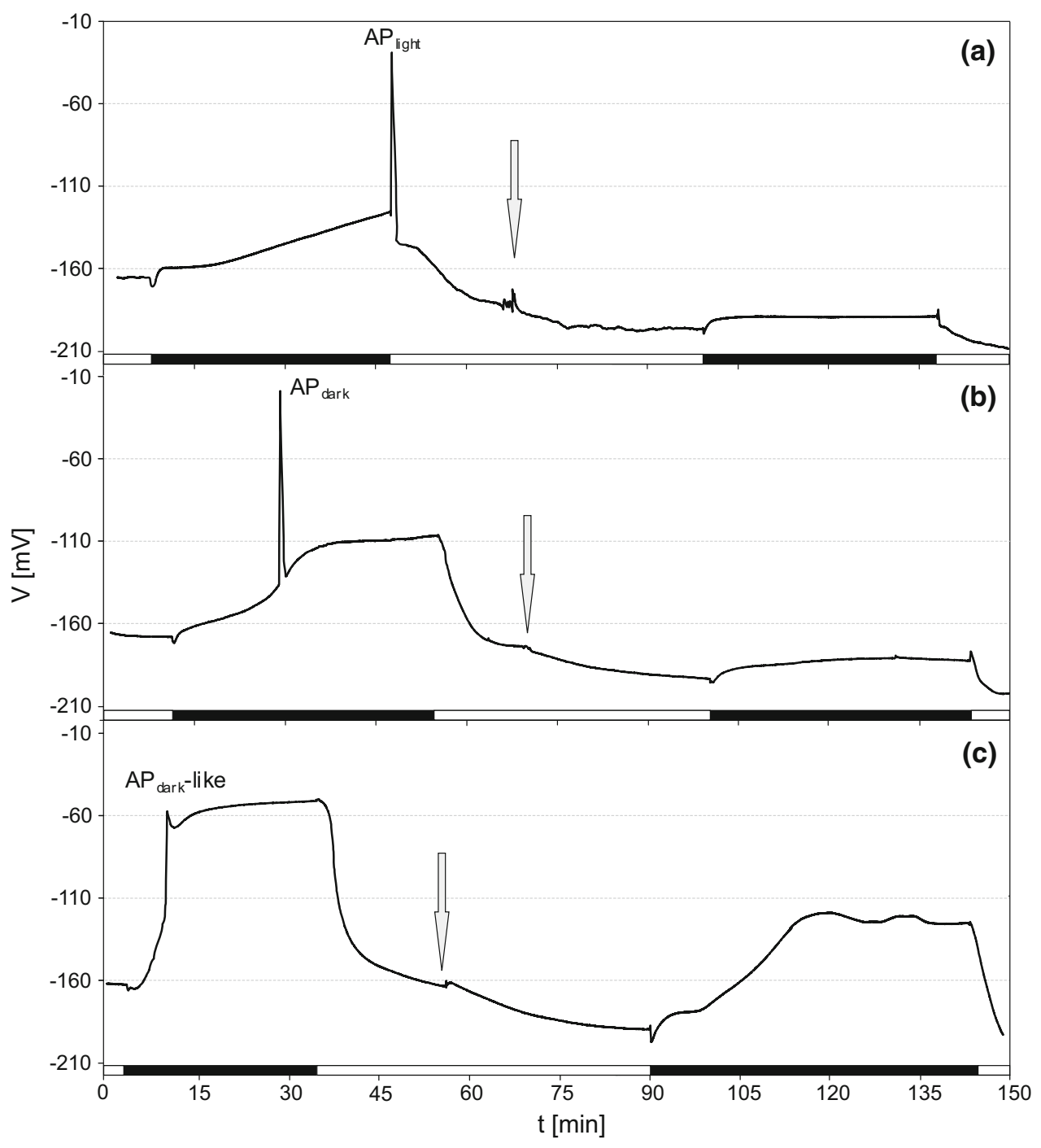

the main cause of $\mathrm{AP}_{\text {dark }}$ and $\mathrm{AP}_{\text {dark }}$-like generation is disturbance in functioning of the electrogenic ion pump, i.e., plasma membrane $\mathrm{H}^{+}$-ATPase. FCCP is regarded as an uncoupling agent, because it disrupts ATP synthesis (Benz and McLaughlin 1983), while DCMU is a specific and sensitive inhibitor of photosynthesis that blocks electron transport from PSII to PSI (Trebst 2007). In our experiments, the application of the proton pump inhibitors (FCCP or DCMU) evoked membrane potential changes and persistent depolarisation that resemble electrical responses recorded after dark stimulation in Marchantia. This may be one of the indirect indications that the turning off the light has an inhibitory effect on the plasma membrane $\mathrm{H}^{+}$-ATPase. In addition, when FCCP or DCMU was used at a concentration that evoked maximal inhibition (at least $50 \mu \mathrm{M}$ FCCP or $20 \mu \mathrm{M}$ DCMU), neither $\mathrm{AP}_{\text {dark }}$ nor $\mathrm{AP}_{\text {dark-like responses and persistent depolarisation after }}$ darkening were observed. This general rule also points to the inhibitory effect of the darkening on the proton pump; it was not possible to block the pump that had already been deactivated chemically. In plants incubated with the lower concentration of FCCP $(20 \mu \mathrm{M})$, darkening evoked only slow membrane potential responses with magnitude depending on the inhibitor concentration. This suggests that, in plants in which FCCP blocked the proton pump only partially, it was possible to deactivate the $\mathrm{H}^{+}$-ATPase completely by turning off the light.

Okumura et al. (2012) have revealed that activation of the proton pump in $M$. polymorpha is a consequence of phosphorylation of penultimate threonine-containing $\mathrm{H}^{+}$ATPase after illumination, whereas darkening evokes gradual dephosphorylation of the $\mathrm{H}^{+}$-ATPase (Okumura et al. 2012). Therefore, inhibition $\mathrm{AP}_{\text {dark }}$ and/or $\mathrm{AP}_{\text {dark }}$-like by DCMU may point to dark-induced stabilization of the dephosphorylated (inactivated) state of the $\mathrm{H}^{+}$-ATPase in $M$. polymorpha cells manifested by the persistent depolarisation. Simultaneously, the absence of $\mathrm{AP}_{\text {dark }} / \mathrm{AP}_{\mathrm{dark}}{ }^{-}$ like after the treatment with the inhibitors is hard to explain 
as the rate of the slow responses is comparable to the rate of initial depolarisation preceding generation of the $\mathrm{AP}_{\text {dark }}$ or $\mathrm{AP}_{\text {dark }}$-like responses in the control plants. Hence, we conclude that not only the rate of the persistent depolarisation, but also the level of the membrane potential of the cells at the moment of turning off the light determines the appearance of the $\mathrm{AP}_{\text {dark }}$ and/or $\mathrm{AP}_{\text {dark-like. Moreover, it is }}$ worth emphasizing that plants generating $\mathrm{AP}_{\text {dark }}$ and/or $\mathrm{AP}_{\text {dark }}$-like exhibited a similar level of the resting potential ( $\sim-170 \mathrm{mV})$. Hence, one can claim that light-induced electrical responses are a more reliable indication of the $\mathrm{H}^{+}$-ATPase status than the RP level. Simultaneously, the high value of $V_{\text {final }}$ in the thalli generating $\mathrm{AP}_{\text {dark }}$-like $t_{1 / 2}^{\infty}$ responses $(-48.8 \pm 2.6 \mathrm{mV})$ suggests that the $\mathrm{K}^{+}$and $\mathrm{H}^{+}$ efflux cannot balance the $\mathrm{Ca}^{2+}$ influx and the $\mathrm{C}^{-}$efflux from an M. polymorpha cell (Trębacz et al. 1994).

In our experiments performed with fusicoccin, i.e., a compound that is regarded to increase acidification of the apoplast by activation of the $\mathrm{H}^{+}$-ATPase (Johansson et al. 1993), we have observed neither $\mathrm{AP}_{\text {dark }}$ nor $\mathrm{AP}_{\text {dark }}$-like responses. Moreover, in plants generating $\mathrm{AP}_{\text {dark }}$ or $\mathrm{AP}_{\text {light }}$ but not $\mathrm{AP}_{\text {dark }}$-like responses before the activator application, the persistent depolarisation was also abolished (Fig. 5). This phenomenon points to more potent fusicoccin activation than darkening-induced inactivation of the $\mathrm{H}^{+}$ATPase in those thalli. However, from the existence of the persistent depolarisation in plants generating $\mathrm{AP}_{\text {dark }}$-like responses in the control solution, it can be deduced that $20 \mu \mathrm{M}$ fusicoccin is not sufficient to activate $\mathrm{H}^{+}$-ATPase if the pump is too "exhausted" to repolarise the membrane potential. $\mathrm{AP}_{\text {light }}$ and GPs were not registered in plants treated with fusicoccin, most probably as a result of a more negative value of the membrane potential than in the control condition. Moreover, taking into account that $\mathrm{AP}_{\text {light }}$ have never been recorded for the membrane potential above $-90 \mathrm{mV}$, we suppose that ion channels engaged in $\mathrm{AP}_{\text {light }}$ formation are these activated in a limited range of membrane potentials, with a specific window of activation. Thus, the mechanism of their activation would resemble the mechanism characteristic for animal thermoreceptors and assume allosteric interaction between voltage and temperature (Voets et al. 2004).

A question can be asked: why do plants generate two types of electrical responses- $\mathrm{AP}_{\text {dark }}$ (single or multiple) or $\mathrm{AP}_{\text {dark }}$-like response after darkening? A straightforward answer to this question is difficult, but it can be supposed that the type of the short-lasting potential changes is depended on the scale of disturbances, most probably at the metabolic level, and its influence on $\mathrm{H}^{+}$-ATPase operation. Plants generating $\mathrm{AP}_{\mathrm{dark}}$-like responses are characterised by metabolic disturbances that cannot be compensated by chemical activation of the proton pump in contrast to slight disorders in plants generating $\mathrm{APs}_{\text {dark }}$. However, it is hard to determine a distinct limit between $\mathrm{AP}_{\text {dark }}$ and $\mathrm{AP}_{\text {dark }}$-like responses. In our experiments, respiration is the only ATPproducing process during darkening. We postulate that the darkening-induced disturbances in respiration mainly result in lowering of the cytoplasmic ATP level and, in consequence, gradual inhibition of $\mathrm{H}^{+}$-ATPase manifested by the membrane potential depolarisation. Tiwari et al. (2002) have demonstrated that the rate of ATP production by mitochondria in cells that do not possess functional chloroplasts depends in inverse proportion on the rate of $\mathrm{H}_{2} \mathrm{O}_{2}$ generation (Tiwari et al. 2002). Moreover, a direct effect of reactive oxygen species (ROS) on the membrane potential has been postulated by Miller et al. (2009). They have revealed that in Arabidopsis thaliana cells, propagation of rapid systemic signals evoked by excess light is accompanied by the accumulation of ROS (Miller et al. 2009). Thus, we suppose that generation of $\mathrm{AP}_{\text {dark }}$ and/or $\mathrm{AP}_{\text {dark }}$-like after darkening is an evidence of a decrease in the ATP level in $M$. polymorpha cells caused, most probably, by oxidative stress evoked by oxygen deficiency in experimental conditions. On the other hand, the plants generated different types of electrical responses, although all measurements were performed in the same arrangement (see "Materials and methods"). The rate of the initial depolarisation may reflect the rate of the $\mathrm{H}^{+}$-ATPase inactivation and seems to be a crucial parameter determining the type of the response, i.e., the faster the persistent depolarisation, the higher the probability of generation of $\mathrm{AP}_{\text {dark }}$-like response (Table 1). Hence, it can be claimed that the slower rate and the smaller magnitude of the persistent depolarisation ensure the better $\mathrm{H}^{+}$-ATPase condition resulting from the higher accessibility of ATP that may provide evidence for efficient respiration.

\section{Conclusions}

Our experiments demonstrate that $M$. polymorpha cells respond to illumination and darkening by generating membrane potential changes. The initial phase of the lightinduced potential changes exhibited differences in polarity, kinetics, and shapes depending on the light-dark or darklight transitions. We conclude that the mechanism engaged in formation of light-induced APs is different from that engaged in formation of the short-lasting potential changes evoked by darkening: $\mathrm{AP}_{\text {dark }}$ and/or $\mathrm{AP}_{\text {dark }}$-like. $\mathrm{H}^{+}$ATPase probably plays a key role in generation of darkinduced the short-lasting potential changes. Hence, $\mathrm{AP}_{\text {dark }}$ and/or $\mathrm{AP}_{\text {dark }}$-like more suitably indicate the metabolic condition of $M$. polymorpha cells than the action potentials evoked by illumination. The absence of $\mathrm{AP}_{\text {dark }}$ and/or 
$\mathrm{AP}_{\text {dark }}$-like probably reflects a high level of ATP and good metabolic condition of the plant cells. However, the biological function of the short-lasting potential changes evoked by darkening needs to be elucidated in the future.

\section{Materials and methods}

\section{Plant material and culture conditions}

Thalli of $M$. polymorpha were collected in a residential area of Lublin city. Gemmae were taken from a male plant from gemmae cups and cultured on peat pellets in a vegetative chamber under white light of $40 \mu \mathrm{mol} \mathrm{m}^{-2} \mathrm{~s}^{-1}$ under a 16:8 h light:dark photoperiod. The vegetative chamber was air-conditioned; the temperature of $22{ }^{\circ} \mathrm{C}$ and humidity of $50-70 \%$ was maintained. After 4-5 weeks of culture, thalli that were about $10-15 \mathrm{~mm}$ in diameter were used for electrophysiological experiments.

\section{Electrophysiological measurements}

The thalli were collected with their rhizoids, and the plants were mounted in a bath chamber. Incubation in a standard solution containing $1 \mathrm{mM} \mathrm{KCl}, 0.1 \mathrm{mM} \mathrm{CaCl}_{2}, 50 \mathrm{mM}$ sorbitol, and Tris/MES ( $\mathrm{pH}$ 7) performed under white light $\left(40 \mu \mathrm{mol} \mathrm{m}{ }^{-2} \mathrm{~s}^{-1}\right)$ lasted $3 \mathrm{~h}$. Sorbitol prevented hypoosmotic shock during the long-lasting immersion and did not influence the resting potential level. Simultaneously, Okumura et al. (2012) have revealed that osmotic shock-depended phosphorylation of $\mathrm{H}^{+}$-ATPase in $M$. polymorpha cells requires over $100 \mathrm{mM}$ mannitol (Okumura et al. 2012). Electrophysiological experiments were performed as described previously (Król and Trębacz 1999). The membrane potential changes were measured with a $100-\mathrm{mM} \mathrm{KCl}$-filled glass microelectrode inserted into individual cells of the thallus and a reference electrode of $\mathrm{Ag} / \mathrm{AgCl}$ placed in a bath. Both electrodes were connected to the amplifier Electrometer Duo 773 (World Precision Instruments, Sarasota, FL, USA). The output signals were digitised by an A/D converter Lab-Trax-4/16 (World Precision Instruments) and recorded with the DATATRAX3 software. For the insertion of the microelectrode into a plant cell, a micromanipulator (DC-3K; Märzhäuser Wetzlar GmbH \& Co.KG, Wetzlar, Germany) was used. The precise localization of the microelectrode tip was not examined; a sudden drop of the membrane potential to the negative value was an indication of the tip location inside the cell.

To analyse the influence of the proton pump regulators on the membrane potential of the $M$. polymorpha cells, the standard solution was additionally supplemented with $20 \mu \mathrm{M}$ FCCP (carbonyl cyanide 4-(trifluoromethoxy)phenylhydrazone) or $20 \mu \mathrm{M}$ DCMU (3-(3,4-dichlorophenyl)-1,1- dimethylurea) or $20 \mu \mathrm{M}$ fusicoccin. All proton pump regulators were prepared as a $20-\mathrm{mM}$ stock solution in ethanol. The final ethanol concentration did not exceed $0.3 \%$. It was checked that ethanol in a concentration up to $1 \%$ evoked neither APs nor depolarisation of the membrane potential in any of the four attempts.

Author contribution statement K. Kupisz planned and performed most of the experiments, interpreted the results, and wrote the draft of the manuscript. H. Dziubińska performed part of the experiments. K. Trębacz verified the paper.

Acknowledgements This research was supported by the Polish National Center for Science (NCN), Grant No. 2013/09/B/NZ1/ 01052 .

Open Access This article is distributed under the terms of the Creative Commons Attribution 4.0 International License (http://crea tivecommons.org/licenses/by/4.0/), which permits unrestricted use, distribution, and reproduction in any medium, provided you give appropriate credit to the original author(s) and the source, provide a link to the Creative Commons license, and indicate if changes were made.

\section{References}

Benz R, McLaughlin S (1983) The molecular mechanism of action of the proton ionophore FCCP (carbonylcyanide p-trifluoromethoxyphenylhydrazone). Biophys J 41:381-398

Cove DJ, Ashton NW (1988) Growth regulation and development in Physcomitrella patens: an insight into growth regulation and development of bryophytes. Bot J Linn Soc 98:247-252

Decker EL, Frank W, Sarnighausen E, Reski R (2006) Moss systems biology en route: phytohormones in Physcomitrella development. Plant Biol 8:397-405

Dziubińska H, Paszewski A, Trębacz K, Zawadzki T (1983) Electrical activity of the liverwort Conocephalum conicum: the all-ornothing law, strength-duration relation, refractory periods and intracellular potentials. Physiol Plant 57:279-284

Elzenga JTM, Prins HBA, Van Volkenburgh E (1995) Light-induced membrane potential changes of epidermal and mesophyll cells in growing leaves of Pisum sativum. Planta 197:127-134

Ermolayeva E, Hohmeyer H, Johannes E, Sanders D (1996) Calciumdependent membrane depolarisation activated by phytochrome in the moss Physcomitrella patens. Planta 199:352-358

Ermolayeva E, Sanders D, Johannes E (1997) Ionic mechanism and role of phytochrome-mediated membrane depolarisation in caulonemal side branch initial formation in the moss Physcomitrella patens. Planta 201:109-118

Favre P, Zawadzki T, Dziubinska H, Trebacz K, Greppin H, Degli Agosti R (1999a) Repetitive action potentials induced in the liverwort Conocephalum conicum (L). Arch Sci 52:187-198

Favre P, Krol E, Stolarz M, Szarek I, Greppin H, Trebacz K, Degli Agosti R (1999b) Action potentials elicited in the liverwort Conocephalum conicum (Hepaticae) with different stimuli. Arch Sci 52:175-185

Ishizaki K, Chiyoda S, Yamato KT, Kohchi T (2008) Agrobacteriummediated transformation of the haploid liverwort Marchantia polymorpha L., an emerging model for plant biology. Plant Cell Physiol 49:1084-1091 
Johansson F, Sommarin M, Larsson C (1993) Fusicoccin activates the plasma membrane $\mathrm{H}^{+}$-ATPase by a mechanism involving the C-Terminal inhibitory domain. Plant Cell 5:321-327

Komatsu A, Terai M, Ishizaki K, Suetsugu N, Tsuboi H, Nishihama R, Yamato KT, Wada M, Kohchi T (2014) Phototropin encoded by a single-copy gene mediates chloroplast photorelocation movements in the liverwort Marchantia polymorpha. Plant Physiol 166:U411-U598

Koselski M, Trebacz K, Dziubinska H, Krol E (2008) Light- and dark-induced action potentials in Physcomitrella patens. Plant Signal Behav 3:13-18

Koselski M, Trebacz K, Dziubinska H (2013) Cation-permeable vacuolar ion channels in the moss Physcomitrella patens: a patch-clamp study. Planta 238:357-367

Koselski M, Dziubinska H, Seta-Koselska A, Trebacz K (2015) A nitrate-permeable ion channel in the tonoplast of the moss Physcomitrella patens. Planta 241:1207-1219

Król E, Trębacz K (1999) Calcium-dependent voltage transients evoked by illumination in the liverwort Conocephalum conicum. Plant Cell Physiol 40:17-24

Król E, Dziubińska H, Trębacz K (2003) Low-temperature induced transmembrane potential changes in the liverwort Conocephalum conicum. Plant Cell Physiol 44:527-533

Król E, Dziubińska H, Trębacz K, Koselski M, Stolarz M (2007) The influence of glutamic and aminoacetic acids on the excitability of the liverwort Conocephalum conicum. J Plant Physiol 164:773-784

Kubota A, Ishizaki K, Hosaka M, Kohchi T (2013) Efficient agrobacterium-mediated transformation of the liverwort Marchantia polymorpha using regenerating thalli. Biosci Biotech Biochem 77:167-172

Kupisz K, Trebacz K (2011) Effect of cold and menthol on membrane potential in plants. Physiol Plant 141:352-360

Lopez-Marques RL, Schiott M, Jakobsen MK, Palgren MG (2004) Structure, function and regulation of primary $\mathrm{H}^{+}$and $\mathrm{Ca}^{2+}$ pumps. In: Blatt MR (ed) Membrane Transport in Plants. Blackwell, Oxford, pp 72-104

Miller G, Schlauch K, Tam R, Cortes D, Torres MA, Shulaev V, Dangl JL, Mittler R (2009) The plant NADPH oxidase RBOHD mediates rapid systemic signaling in response to diverse stimuli. Sci Signal. doi:10.1126/scisignal.2000448

Mimura T, Tazawa M (1986) Analysis of rapid light-induced potential change in cells of Chara corallina. Plant Cell Physiol 27:895-902

Nishihama R, Ishizaki K, Hosaka M, Matsuda Y, Kubota A, Kohchi T (2015) Phytochrome mediated regulation of cell division and growth during regeneration and sporeling development in the liverwort Marchantia polymorpha. J Plant Res 128:407-421

Oda K, Yamato K, Ohta E, Nakamura Y, Takemura M, Nozato N, Akashi K, Kanegae T, Ogura Y, Kohchi T, Ohyama K (1992) Complete nucleotide sequence of the mitochondrial DNA from a liverwort, Marchantia polymorpha. Plant Mol Biol Rep 10:105-163

Ohyama K, Fukuzawa H, Kohchi T, Shirai H, Sano T, Sano S, Umesono K, Shiki Y, Takeuchi M, Chang Z, Aota S, Inokuchi H, Ozeki H (1986) Chloroplast gene organization deduced from complete sequence of liverwort Marchantia polymorpha chloroplast DNA. Nature 322:572-574

Okada S, Fujisawa M, Sone T, Nakayama S, Nishiyama R, Takenaka M, Yamaoka S, Sakaida M, Kono K, Takahama M, Yamato KT, Fukuzawa H, Brennicke A, Ohyama K (2000) Construction of male and female PAC genomic libraries suitable for identification of Y-chromosome-specific clones from the liverwort, Marchantia polymorpha. Plant J 24:421-428

Okumura M, Inoue S, Takahashi K, Ishizaki K, Kohchi T, Kinoshita $\mathrm{T}$ (2012) Characterization of the plasma membrane $\mathrm{H}^{+}$-ATPase in the liverwort Marchantia polymorpha. Plant Physiol 159:826-834

Oldenburg DJ, Bendich AJ (1998) The structure of mitochondrial DNA from the liverwort, Marchantia polymorpha. J Mol Biol 276:745-758

Orlova OV, Pyatygin SS, Opritov VA, Kalinin VA (1997) Importance of ATP-dependent $\mathrm{H}^{+}$-pump for stabilizing electrogenesis at plasmalemma in Cucurbita pepo L. cells. Russ J Plant Physiol 44:785-790

Paszewski A, Dziubińska H, Trębacz K, Zawadzki T (1982) Electrical activity of the liverwort Conocephalum conicum: method of investigation and general characteristics of excitation. Physiol Plant 54:83-87

Plieth C, Sattelmacher B, Hansen UP (1998) Light-induced cytosolic calcium transients in green plant cells. II. The effect on a $\mathrm{K}^{+}$ channel as studied by a kinetic analysis in Chara corallina. Planta 207:52-59

Reski R (1999) Molecular genetics of Physcomitrella. Planta 208:301-309

Szarek I, Trebacz K (1999) The role of light-induced membrane potential changes in guttation in gametophytes of Asplenium trichomanes. Plant Cell Physiol 40:1280-1286

Takenaka M, Yamaoka S, Hanajiri T, Shimizu-Ueda Y, Yamato KT, Fukuzawa H, Ohyama K (2000) Direct transformation and plant regeneration of the haploid liverwort Marchantia polymorpha $\mathrm{L}$. Transgenic Res 9:179-185

Tiwari BS, Belenghi B, Levine A (2002) Oxidative stress increased respiration and generation of reactive oxygen species, resulting in ATP depletion, opening of mitochondrial permeability transition, and programmed cell death. Plant Physiol 128:1271-1281

Trębacz K, Zawadzki T (1985) Light-triggered action potentials in the liverwort Conocephalum conicum. Physiol Plant 64:482-486

Trębacz K, Tarnecki R, Zawadzki T (1989a) Characteristics of the light-induced generator potentials in the liverwort Conocephalum conicum. Physiol Plant 75:20-23

Trębacz K, Tarnecki R, Zawadzki T (1989b) The effects of ionic channel inhihitors and factors modifying metabolism on the excitability of the liverwort Conocephalum conicum. Physiol Plant 75:24-30

Trębacz K, Simonis W, Schoenknecht G (1994) Cytoplasmic Ca ${ }^{2+}$, $\mathrm{K}^{+}, \mathrm{CI}^{-}$, and $\mathrm{NO}_{3}{ }^{-}$activities in the liverwort Conocephalum conicum L. at rest and during action potentials. Plant Physiol 106:1073-1084

Trębacz K, Simonis W, Schönknecht G (1997) Effects of anion channel inhibitors on light induced potential changes in the liverwort Conocephalum conicum. Plant Cell Physiol 38:550-557

Trebst A (2007) Inhibitors in the functional dissection of the photosynthetic electron transport system. Photosynth Res 92:217-224

Tsuboyama-Tanaka S, Kodama Y (2015) AgarTrap-mediated genetic transformation using intact gemmae/gemmalings of the liverwort Marchantia polymorpha L. J Plant Res 128:337-344

Voets T, Droogmans G, Wissenbach U, Janssens A, Flockerzi V, Nilius B (2004) The principle of temperature-dependent gating in cold- and heat-sensitive TRP channels. Nature 430:748-754

Yamato KT, Ishizaki K, Fujisawa M et al (2007) Gene organization of the liverwort $\mathrm{Y}$ chromosome reveals distinct sex chromosome evolution in a haploid system. Proc Natl Acad Sci USA 104:6472-6477

Zawadzki T, Trębacz K (1985) Extra- and intracellular measurements of action potentials in the liverwort Conocephalum conicum. Physiol Plant 64:477-481 